\title{
Correction to: Understanding the Social Implications of the Digital Transformation: Insights from Four Case Studies on the Role of Social Innovation to Foster Resilience of Society
}

Gianluca Misuraca, Giulio Pasi, and Gianluigi Viscusi

\author{
Correction to: \\ Chapter "Understanding the Social Implications of the Digital \\ Transformation: Insights from Four Case Studies on the \\ Role of Social Innovation to Foster Resilience of Society" \\ in: N. Edelmann et al. (Eds.): Electronic Participation, \\ LNCS 11021, https://doi.org/10.1007/978-3-319-98578-7_12
}

The original version of the paper starting on p. 145 was revised. The last sentence of the abstract part on p. 145 was incorrect. Instead of "Based on an extensive body of literature reviewed the framework proposed for interpreting the effects of social innovation in fostering resilience fare discussed through four case studies" it should be read as "Based on an extensive body of literature reviewed, the framework proposed for interpreting the effects of social innovation in fostering resilience and its application are discussed through four case studies."

The original chapter was corrected.

The updated online version of this chapter can be found at https://doi.org/10.1007/978-3-319-98578-7_12

(C) IFIP International Federation for Information Processing 2018

Published by Springer Nature Switzerland AG 2018. All Rights Reserved

N. Edelmann et al. (Eds.): ePart 2018, LNCS 11021, p. E1, 2018.

https://doi.org/10.1007/978-3-319-98578-7_13 